\section{Kidney \\ Blood Pressure Research}

\title{
Nonalcoholic Fatty Liver Disease (NAFLD) And Cardiovascular Risk In Renal Transplant Recipients
}

\author{
Ivana Mikolasevic ${ }^{a}$ Sanjin Racki ${ }^{a} \quad$ Luka Zaputovic $^{b}$ Vesna Lukendac \\ Branka Sladoje-Martinovic ${ }^{a}$ Lidija Orlic $^{a}$
}

aDepartment of Nephrology, Dialysis and Transplantation; 'bepartment of Cardiology, University Hospital Rijeka, Rijeka; 'Department of Internal Medicine, General Hospital "Dr. Josip Bencevic",

Slavonski Brod, Croatia

\section{Key Words}

Cardiovascular disease $\bullet$ Renal transplant recipients $\bullet$ Nonalcoholic fatty liver disease (NAFLD)

- Transient elastography

\begin{abstract}
Background/Aims: Renal transplant recipients (RTRs) are at high risk for cardiovascular (CVD) mortality. Recently, nonalcoholic fatty liver disease (NAFLD) has been recognized as a new risk factor for adverse CVD events in the general population. We examined whether transient elastography (TE) defined NAFLD was associated with atherosclerosis in RTRs, as measured by ultrasound in the carotid arteries. Methods: Carotid atherosclerosis was assesses in 71 RTRs with a TE proven NAFLD. With the help of TE liver stiffness was used to assess liver fibrosis and Controlled Attenuation Parameter (CAP) was used to detect and quantify liver steatosis. NAFLD was defined by the presence of steatosis with CAP values $\geq 238 \mathrm{~dB} \cdot \mathrm{m}^{-1}$. Results: RTRs with NAFLD showed more carotid atherosclerosis than RTRs without NAFLD. RTRs-NAFLD patients had the mean intima-media measurements (ITM) of $1.1 \pm 0.1 \mathrm{~mm}$ and that was statistically significant higher than the mean ITM founded in RTRs without NAFLD $(1.1 \pm 0.1 \mathrm{vs.} 0.9 \pm 0.1 \mathrm{~mm}$; $p<0.0001$ ). Furthermore, RTRs-NAFLD patients had statistically significant higher prevalence of plaques in comparison with RTRs without NAFLD $(p=0.021)$. Conclusion: We showed for the first time that carotid atherosclerosis is advanced in RTRs with NAFLD. Detection of NAFLD by TE should alert to the existence of an increased cardiovascular risk in RTRs.
\end{abstract}




\section{Kidney Blood Pressure Research}

Kidney Blood Press Res 2014;39:308-314

DOI: $10.1159 / 000355808$
Published onlIne: September 19, 2014

(C) 2014 S. Karger AG, Base

www.karger.com/kbr

Mikolasevic/Racki/Zaputovic/Lukenda/Sladoje-Martinovic/Orlic: NAFLD, Cardiovascular Risk and Renal Transplantation

\section{Introduction}

Despite all improvements in transplant medicine, renal transplant recipients (RTRs) have a high risk for cardiovascular mortality. A high prevalence of cardiovascular complications in RTR is explained by cardiovascular risk factors present before transplantation, in addition to the development of new risk factors as well as worsening of preexisting risk factors after transplantation [1].

Nonalcoholic fatty liver disease (NAFLD) is a highly prevalent condition characterized by macrovesicular steatosis of the liver that occurs in people who do not consume large amounts of alcohol. Insulin resistence (IR) plays an important role in the pathogenesis of NAFLD and is closely linked to metabolic syndrome (MS) and its manifestation: obesity, diabetes mellitus type 2, dyslipidemia, and hypertension. In recent years, NAFLD has been considered to be the liver manifestation of MS. The current importance of NAFLD and its link to MS has encouraged an interest in its possible role in the development of atherosclerosis [2-4]. Recent data supports the hypothesis that NAFLD itself might contribute to a higher risk of CVD independent of other prognostic risk factors. So, the development of NAFLD and fibrosis identifies an at-risk group with increased risk of cardiovascular and liver-related deaths [2-6]. In recent years, the possible link between NAFLD and chronic kidney disease (CKD) has also attracted research interest $[7,8]$.

Although today there is no clear recommendation whether liver biopsy is necessary to confirm the diagnosis of NAFLD, it still represents the current gold standard for evaluating fibrosis, steatosis and other histological lesions in a liver biopsy. But it has some limitations, such as its invasive nature, and it is prone to significant sampling error. Namely, the average size of a biopsy is $15 \mathrm{~mm}$ in length, which represents only 1/50,000 the size of the liver parenchyma. Moreover, repetition of a liver biopsy to monitor changes in steatosis is difficult. Therefore, in recent years some non-invasive radiographic techniques have been intensively investigated in assessment of hepatic steatosis, such as computed tomography and protonmagnetic resonance spectroscopy (H-MRS). But the use of these methods is limited by, in some cases, high cost, restricted availability, operator dependence and poor sensitivity. Also, these methods cannot simultaneously assess liver fibrosis and steatosis. On the other hand, the sensitivity of the ultrasonography for detection of hepatic steatosis is between $93 \%$ and $100 \%$ if the fat content in hepatic parenchyma is $>33 \%$. It is a relatively subjective method and is therefore prone to sampling error. To overcome these limitations, a novel technology called transient elastography (TE) (Fibroscan $®$ ) has been developed.

It has been shown promising results in the assessment of liver fibrosis. Specifically, TE has been incorporated into the international guidelines for chronic hepatitis B and/or C. Moreover, recent studies showed that a novel physical parameter, called the Controlled Attenuation Parameter (CAP), evaluated with TE could efficiently separate steatosis grades. According to the literature, a cut-off value of $238 \mathrm{~dB} / \mathrm{m}$ has sensitivity of $90 \%$ and specificity of $81 \%$ to detect low-grade steatosis ( $<10 \%)$. It is based on the properties of ultrasonic signals acquired by the Fibroscan ${ }^{\circledR}$ machine. This procedure allows simultaneous measurement of liver stiffness and CAP in the same liver volume. TE measures liver volume that is at least 100 times larger than a biopsy sample. It is fast, painless, easily obtained and more cost-effective than a liver biopsy [9-11].

The components of MS are highly present after kidney transplantation, mainly due to use of immunosuppressive therapy. Considering the fact that those disorders are strongly associated with NAFLD development in general population, we believe that RTRs will have higher incidence of NAFLD than general population [1]. Recently, we have evaluated frequency of NAFLD in RTRs [12]. To this end we used TE (Fibroscan®-CAP). In this crosssection analysis we have found that NAFLD was present in $57.5 \%$ of RTRs. Consequently the presence of NAFLD in RTRs could be a strong predictor of CVD risk.

Therefore, we aimed to investigate whether there is a significant association between the presences of TE defined NAFLD in RTRs and increased CVD risk in RTRs. To this end, we 


\section{Kidney Blood Pressure Research}

Kidney Blood Press Res 2014;39:308-314

\begin{tabular}{l|l}
\hline DOI: $10.1159 / 000355808$ & (c) 2014 S. Karger AG, Basel
\end{tabular}

Published onlıne: September 19, 2014

www.karger.com/kbr

Mikolasevic/Racki/Zaputovic/Lukenda/Sladoje-Martinovic/Orlic: NAFLD, Cardiovascular Risk and Renal Transplantation

investigate the association of NAFLD in RTRs with carotid intima-media thickness (ITM) and plaque as surrogate measures of increased CVD risk.

\section{Materials and Methods}

Seventhly-six renal transplant recipients with a functioning graft for more than 1 year who came for regular nephrology controls were enrolled in this cross-sectional study. The exclusion criteria were: chronic hepatitis B and/or C virus infection, excessive alcohol abuse, presence of other autoimmune or cholestatic liver disease, drug induced liver disorders, clinical and laboratory signs of impaired synthetic and metabolic liver function and technical reasons (failed TE). Considering the above, 71 patients were enrolled in the study.

Overweight was defined as a BMI of at least $25 \mathrm{~kg} / \mathrm{m}^{2}$, diabetes as fasting glucose $\geq 7.1 \mathrm{mmol} / \mathrm{L}$ or drug treatment, while dyslipidemia was defined by triglycerides $\geq 1.7 \mathrm{mmol} / \mathrm{L}$ or drug treatment and/or $\mathrm{HDL}<1 \mathrm{mmol} / \mathrm{L}$ in men and $<1.29$ in women or drug treatment. Arterial hypertension was considered if the patients had blood pressure $\geq 130 / 80 \mathrm{mmHg}$ or by the use of antihypertensive drugs.

Transient elastography was performed in all patients. Liver stiffness was used to assess liver fibrosis and Controlled Attenuation Parameter (CAP) to detect and quantify liver steatosis by using TE (Fibroscan ${ }^{\circledR}$, Echosense, Paris, France). The cut-off value for defining liver steatosis was CAP $\geq 238 \mathrm{~dB} \cdot \mathrm{m}^{-1}$ and cut-off value for defining the presence of fibrosis was liver stiffness of $>7 \mathrm{kPa}$. The diagnosis of NAFLD was defined according to TE findings with the presence of steatosis (CAP $\geq 238 \mathrm{~dB} \cdot \mathrm{m}^{-1}$ ), with or without any stage of fibrosis (which was defined with the presence of liver stiffness $>7 \mathrm{kPa}$ ) and exclusion of other secondary causes of chronic liver disease $[9,11]$. At the same time a carotid ultrasound with a 9-MHz multifrequency transducer was performed in all patients to investigate the association of NAFLD with carotid intima-media thickness (ITM) and plaque as surrogate measures of increased CVD risk. The present analysis used the average of 10 electronic calipers ITM measurements from the far wall of the distal $10 \mathrm{~mm}$ of left and right common carotid arteries at a site free from any discrete plaque. A plaque was defined as a focal thickening of $\geq 1.2 \mathrm{~mm}$. These results were correlated with the presence of NAFLD.

\section{Statistical Analysis}

Statistical analysis of data was performed by using descriptive statistics. Categorical variables were tested by chi-square test or Fisher's exact test. Difference of two independent groups was performed using t-test or ANOVA. The Pearson or Sperman correlation coefficient was used to express correlations between variables. Variables that were found significantly predicting carotid atherosclerosis on univariate analysis were entered into multivariate analysis. P-value $<0.05$ was considered to be statistically significant. Statistical analysis was made by using MedCalc statistical software package, version 10 (MedCalc, Mariakerke, Belgium).

\section{Results}

The average age of the 71 (39 male and 32 female) enrolled RTRs was $55.7 \pm 11.4$ years. Thirty-eight of them (53.5\%) had CAP > $238 \mathrm{~dB} \cdot \mathrm{m}^{-1}$ and had NAFLD by definition. Thirteen patients $(18.3 \%)$ with $\mathrm{CAP} \geq 238 \mathrm{dBm}_{-1}$ had liver stiffness of more than $7 \mathrm{kPa}$. Demographic characteristics of the remaining 71 patients stratified by NAFLD status are shown in Table 1 . There was no statistically significant difference between the RTRs with or without NAFLD related to age, gender, etiology of ESRD or due to duration of RRT prior to transplantation and time since transplantation. Diabetes mellitus $(p=0.017)$ and arterial hypertension ( $\mathrm{p}=0.02$ ) were more frequently observed in RTRs with NAFLD, while there was no significant differences due to dyslipidemia between two subgroups of RTRs. RTRs-NAFLD had statistically significant higher values of BMI in comparison to RTRs without NAFLD $(\mathrm{p}=0.02)$.

We were interested to explore whether NAFLD in RTRs is associated with advanced atherosclerosis. We have founded that RTRs with NAFLD showed more carotid atherosclerosis 


\section{Kidney \\ Blood Pressure Research}

Table 1. Demographic characteristic of the analyzed patients

\begin{tabular}{|c|c|c|c|c|}
\hline & $\begin{array}{c}\text { All RTRs } \\
\mathrm{N}=71\end{array}$ & $\begin{array}{c}\text { NAFLD-RTRs } \\
\mathrm{N}=38\end{array}$ & $\begin{array}{l}\text { Non-NAFLD- } \\
\text { RTRs, N=33 }\end{array}$ & $\mathrm{p}$ \\
\hline GENDER (M:F) & $39: 32$ & $17: 21$ & $12: 21$ & NS \\
\hline Age (years) & $55.7 \pm 11.4$ & $56.7 \pm 10$ & $54.7 \pm 12.8$ & NS \\
\hline \multicolumn{5}{|l|}{ Etiology } \\
\hline Nondiabetic nephropathy, n (\%) & $15(21.1 \%)$ & $5(13.2 \%)$ & $10(30.3 \%)$ & NS \\
\hline Chronic GN, n (\%) & $20(28.2 \%)$ & $10(26.3 \%)$ & $10(36.4 \%)$ & NS \\
\hline Chronic nephritis & $12(16.9 \%)$ & $6(15.8 \%)$ & $6(18.2 \%)$ & NS \\
\hline Polycystic kidney disease, n (\%) & $13(18.3 \%)$ & $10(26.3 \%)$ & $3(9.1 \%)$ & NS \\
\hline Other, n (\%) & $11(15.5 \%)$ & $7(18.4 \%)$ & $4(12.1 \%)$ & NS \\
\hline Duration of RRT prior to tx (m) & $44.3 \pm 38.1$ & $42.8 \pm 33.2$ & $46.1 \pm 43$ & NS \\
\hline Time since tx & $65.2 \pm 59.1$ & $67.1 \pm 65.7$ & $63.1 \pm 52.2$ & NS \\
\hline DD vs. LDR & 68 vs. 3 & 37 vs. 1 & 31 vs. 2 & NS \\
\hline Donor age (years) & $47.8 \pm 7.8$ & $48.8 \pm 9.2$ & $46.8 \pm 8$ & NS \\
\hline Tacrolimus therapy, n (\%) & $53(74.6 \%)$ & $28(73.7 \%)$ & $25(75.8 \%)$ & NS \\
\hline Tacrolimus concentration (ug/L) & $6.9 \pm 1.9$ & $6.8 \pm 1.4$ & $7.0 \pm 1.3$ & NS \\
\hline Cyclosporine therapy, n (\%) & $18(25.4 \%)$ & $10(26.3 \%)$ & $8(24.2 \%)$ & NS \\
\hline Cyclosporine concentration (nmol/L) & $111 \pm 20$ & $113 \pm 19$ & $109 \pm 20$ & NS \\
\hline Prednisone therapy, n (\%) & $66(93 \%)$ & $36(94.7 \%)$ & $30(90.9 \%)$ & NS \\
\hline Arterial hypertension, $\mathrm{n}(\%)$ & $65(91.5 \%)$ & $38(100 \%)$ & $27(81.8 \%)$ & 0.02 \\
\hline Serum creatinine & $125 \pm 28.3$ & $120 \pm 24.2$ & $128 \pm 31.2$ & NS \\
\hline DM, n (\%) & $14(19.7 \%)$ & $12(31.6 \%)$ & $2(6.1 \%)$ & 0.017 \\
\hline Dyslipidemia, n (\%) & $55(77.4 \%)$ & $35(92.1 \%)$ & $20(60.6 \%)$ & NS \\
\hline Body mass index $\left(\mathrm{kg} / \mathrm{m}^{2}\right)$ & $26 \pm 1.6$ & $26.4 \pm 1.5$ & $25.5 \pm 1.1$ & 0.02 \\
\hline
\end{tabular}

*Male (M); female (F); renal replacement therapy (RRT), glomerulonephritis (GN); transplantation (tx); months (m); deceased donor (DD); living-related donor (LRD); diabetes mellitus (DM)

Table 2. Carotid ITM and plaque in RTRs with NAFLD versus RTRs without NAFLD

\begin{tabular}{lccc}
\hline CRITERION & $\begin{array}{c}\text { RTRs-NAFLD } \\
(\mathrm{n}=38)\end{array}$ & $\begin{array}{c}\text { Non-NAFLD } \\
\text { RTRs }(\mathrm{n}=33)\end{array}$ & $\mathrm{p}$ \\
\hline Carotid ITM $(\mathrm{cm})$ & $1.1 \pm 0.1$ & $0.9 \pm 0.1$ & $<0.0001$ \\
Carotid plaque, $\mathrm{n}(\%)$ & $23(60.5 \%)$ & $10(30.3 \%)$ & 0.021 \\
\hline *Intimae media thickness (ITM); nonalcoholic fatty liver disease (NAFLD) \\
\hline
\end{tabular}

than RTRs without NAFLD. Namely, RTRsNAFLD patients had the mean ITM of $1.1 \pm 0.1$ $\mathrm{mm}$ and that was statistically significant higher than the mean ITM measurements founded in RTRs without NAFLD $(1.1 \pm 0.1$ vs. $0.9 \pm 0.1 \mathrm{~mm} ; \mathrm{p}<0.0001$ ) (Table 2; Figure 1). Furthermore, RTRs-NAFLD patients had statistically significant higher prevalence of plaques in comparison with RTRs without NAFLD (60.5\% vs. $30.3 \%$; $p=0.021$ ) (Table 2; Figure 2.).

In the next step we investigated the association among CAP and ITM measurements. There was a highly significant, positive, correlation between CAP and ITM measurements ( $r=0.674 ; p<0.0001$ (Figure 3 ).

Various baseline demographic and clinical variables were analyses as possible predictors of carotid atherosclerosis. On

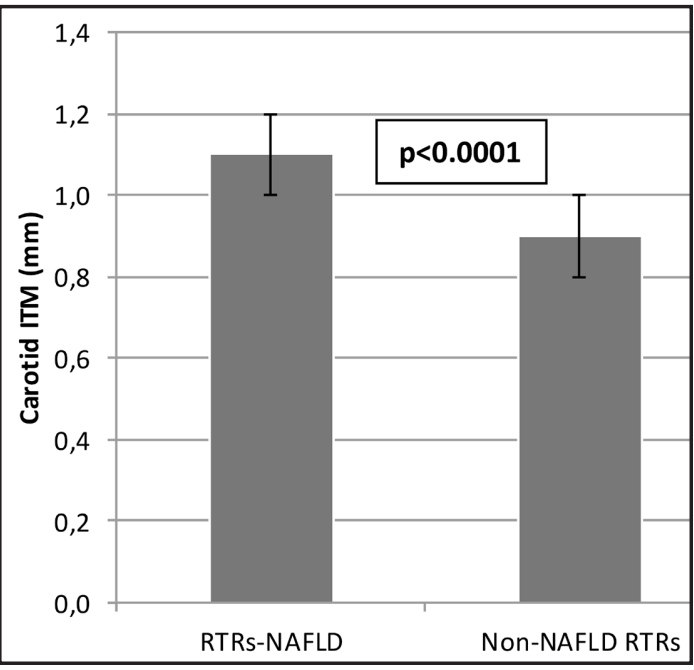

Fig. 1. Graph of carotid ITM in RTRs with NAFLD and RTRs without NAFLD. 


\section{Kidney \\ Blood Pressure Research}

Kidney Blood Press Res 2014;39:308-314

\begin{tabular}{l|l}
\hline DOI: $10.1159 / 000355808$ & (c 2014 S. Karger AG, Basel
\end{tabular}

Published online: September 19, 2014

www.karger.com/kbr

Mikolasevic/Racki/Zaputovic/Lukenda/Sladoje-Martinovic/Orlic: NAFLD, Cardiovascular Risk and Renal Transplantation
Fig. 2. Graph of carotid plaques (in percentage) in RTRs with NAFLD and RTRs without NAFLD; $\mathrm{p}=0.021$.

$(\mathrm{p}<0.0001)$, DM $(\mathrm{p}<0.0001)$, dyslipidemia $(\mathrm{p}<0.0001)$ and longer RRT treatment before transplantation $(\mathrm{p}<0.0001)$ were found to be significantly associated with higher ITM, while higher BMI $(\mathrm{p}<0.0001)$, presence of NAFLD $(\mathrm{p}<0.0001)$ and dyslipidemia $(\mathrm{p}=0.001)$, longer RRT before transplantation $(\mathrm{p}<0.0001)$ and male gender $(\mathrm{p}<0.0001)$ were found to be significantly associated with plaque occurrence. When these significant

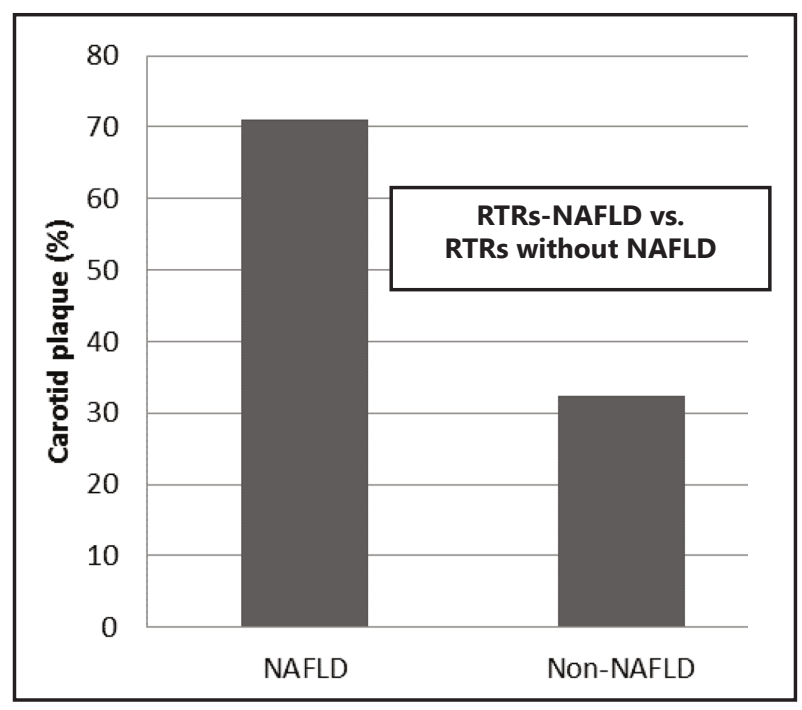

Fig. 3. The correlation between CAP values and carotid ITM.

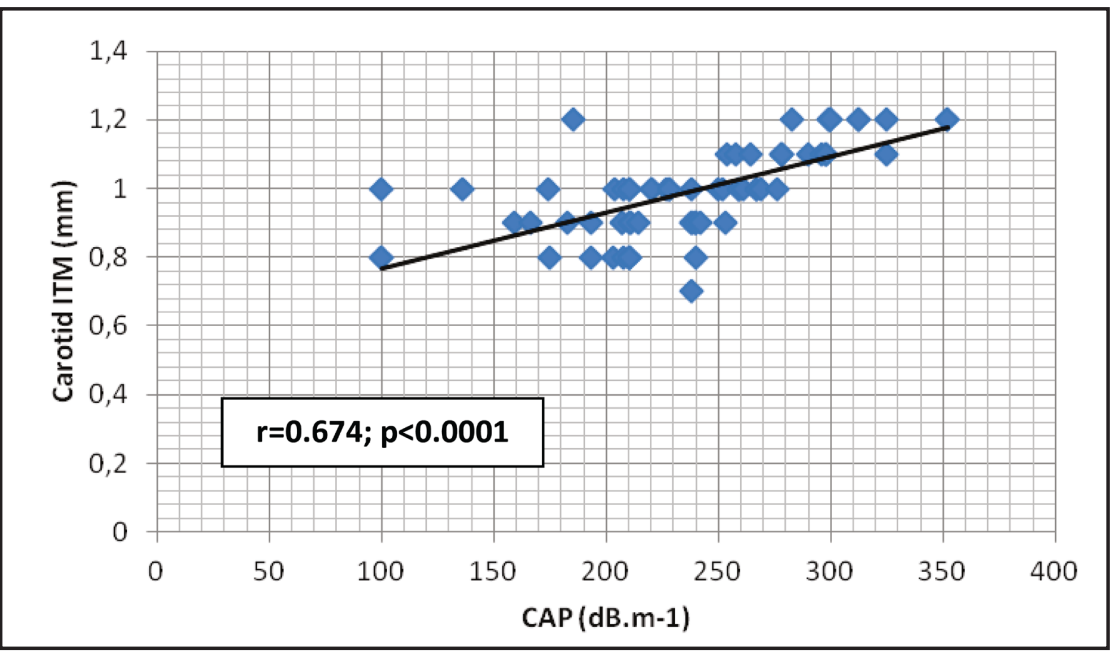

variables were entered into multivariate analysis, only NAFLD was factor that contributes to plaque occurrence $(p=0.0010)$ as well as to higher ITM values ( $p=0.0007)$.

\section{Discussion}

Transplant recipients have a high rate of cardiovascular deaths in comparison to general population. This is mainly a consequence of an exacerbation of traditional risk factors caused by immunosuppressive drugs. An increased risk of CVD in RTRs cannot be fully explained only by traditional risk factors. In recent years, a number of non-traditional risk factors such as reduced kidney function following transplantation, rejection, elevated levels of lipoprotein (a), elevated C-reactive protein (CRP) and interleukin-6 (IL-6) levels and proteinuria have been identified [12-15]. Search for new causes of CVD in RTRs has attracted further research.

On the other hand, due to underlying metabolic disorders mentioned above, NAFLD patients are expected to have a higher risk of CVD, even without MS. According to literature, there is a strong association between liver histology in NAFLD patients and greater carotid ITM and plaque and lower endothelial flow-mediated vasodilatation (as a marker of subclinical atherosclerosis). Francanzani et al [16] showed that steatosis is highly associated to ITM and 


\section{Kidney Blood Pressure Research}

Kidney Blood Press Res 2014;39:308-314

\begin{tabular}{l|l}
\hline DOI: $10.1159 / 000355808$ & (C) 2014 S. Karger AG, Basel
\end{tabular}

Published online: September 19, 2014

www.karger.com/kbr

Mikolasevic/Racki/Zaputovic/Lukenda/Sladoje-Martinovic/Orlic: NAFLD, Cardiovascular Risk and Renal Transplantation

to an increased risk of atherosclerosis in subjects with MS. Similar results were showed by authors of recent studies [17-21]. Furthermore, it has been shown that NAFLD is not merely a marker of CVD, but it may actually be actively involved in its pathogenesis. All of these studies confirm the hypothesis that NAFLD-patients have a higher risk of suffering from CVD [16-21]. To our knowledge, this is the first study that has been investigated the association among TE defined NAFLD and carotid atherosclerosis in RTRs. Our results showed that RTRs with NAFLD showed more carotid atherosclerosis than RTRs without NAFLD. In our study, carotid ITM was noticeably higher in RTRs with NAFLD than in RTRs without NAFLD. Also, the prevalence of plaques was higher in RTRs with NAFLD in comparison with RTRs without NAFLD. Finally, we have founded highly significant, positive, correlation between CAP and ITM measurements. These findings suggest that NAFLD could be associated with increased CVD risk in RTRs. The results of the present study are in accordance with recent studies that were investigated the association of NAFLD with the risk of CVD [15-20]. However, to prove this contention, larger numbers of RTRs with and without NAFLD need to be studied for carotid atherosclerosis or other cardiovascular risk markers.

A probable explanation for the marked proatherogenic effect of NAFLD is sub-chronic liver inflammation in NAFLD/NASH patients that leads and contributes to dyslipidemia, inflammation, enhanced oxidative stress and endothelial dysfunction. Namely, the liver is the central organ for the production of various classical biomarkers of inflammation and endothelial dysfunction, the secretion of which partly depends on factors that are up regulated in the presence of insulin resistance and the metabolic syndrome. Today, there is growing evidence suggesting that in patients with NAFLD/NASH there is an increased production and release of various proinflammatory cytokines. These include increased reactive oxygen species, TNF-alpha, TGF-beta, plasminogen activator inhibitor-1, C-reactive protein (CRP), IL-6 and etc produced by hepatocytes and non-parenhimal-cells, including Kupffer cells and hepatic sttelate cells. Another potential mechanism by which NAFLD may increase CVD risk is abnormal lipoprotein metabolism. Therefore, enhanced oxidative stress, inflammation with release of inflammatory cytokines and abnormal lipoprotein metabolism could account for the proatherogenic effect of NAFLD [5, 13, 22-24].

Our study has some limitations such as its cross-sectional design and relatively small number of patients. Furthermore, the diagnosis of NAFLD was based on the exclusion of known etiologic factors of liver disease and on TE findings (Fibroscan ${ }^{\circledR}-\mathrm{CAP}$ ), but was not confirmed by liver biopsy for ethical reasons. However, TE is more and more used in everyday clinical practice as an alternative method to liver biopsy. But, on the other hand it has several strengths; it shows, for the first time those RTRs with NAFLD show an advanced carotid atherosclerosis.

\section{Conclusion}

Accordnig to our results, NAFLD should be considered and investigated as a new important risk factor for increased CVD risk in renal transplant recipients. Further studies are needed to investigate and to confirm these observations. Nonalcoholic fatty liver disease is a feature of the MS and it's detection by TE should alert to the existence of an increased cardiovascular risk in RTRs. The screening of these patients for NAFLD can be beneficial for the use of TE (CAP) as a screening method which is non-invasive, quick method and may be repeated. Despite all limitations in our study, data showed a significant association between NAFLD as a risk factor for CVD.

\section{Disclosure Statement}

The authors of this manuscript state that they do not have any conflict of interests and nothing to disclose. 


\section{Kidney \\ Blood Pressure Research}

Kidney Blood Press Res 2014;39:308-314

\begin{tabular}{l|l}
\hline DOI: $10.1159 / 000355808$ & (C) 2014 S. Karger AG, Basel
\end{tabular}

Published onlıne: September 19, 2014

www.karger.com/kbr

Mikolasevic/Racki/Zaputovic/Lukenda/Sladoje-Martinovic/Orlic: NAFLD, Cardiovascular Risk and Renal Transplantation

\section{References}

1 Mikolasevic I, Racki S, Lukenda V, Pavletic-Persic M, Milic S, Orlic L: Non-alcoholic fatty liver disease; a part of the metabolic syndrome in the renal transplant recipient and possible cause of an allograft dysfunction. Med Hypotheses 2014;82:36-39.

2 Dowma JK, Tomlinson JW, Newsome N: Systematic review: the diagnosis and staging of non-alcoholic fatty liver disease and non-alcoholic steatohepatitis. Aliment Pharmacol Ther 2011;33:525-540.

-3 Targher G, Arcaro G: Non-alcoholic fatty liver disease and increased risk of cardiovascular disease. Atherosclerosis 2007;191:235-240.

4 Farrel GC, Larter CZ: Nonalcoholic fatty liver disease: from steatosis to cirrhosis. Hepatology 2006;43:S99-S112.

5 Cheung 0, Sanyal AR: Recent advances in nonalcoholic fatty liver disease. Curr Opin Gastroenterol 2010;26:202-208.

6 Mikolasevic I, Racki S, Zaputovic l, Lukenda V, Milic S, Orlic L: Nonalcoholic fatty liver disease (NAFLD); a new risk factor for adverse cardiovascular events in dialysis patients. Med Hypothesis 2014;82:205-208.

7 Targher G, Bertolini L, Rodella S, Lippi G, Zoppini G, Chonchol M: Relationship between kidney function and liver histology in subjects with nonalcoholic steatohepatitis. Clin J Am Soc Nephrol 2010;5:2166-2171.

8 Mikolasevic I, Racki S, Bubic I, Jelic I, Stimac D, Orlic L: Chronic kidney disease and nonalcoholic fatty liver disease proven by transient elastography. Kidney Blood Press Res 2013;37:305-310.

-9 Sasso M, Miette V, Sandrin L, Beaugrand M: The controlled attenuation parameter (CAP): a novel tool for the non-invasive evaluation of steatosis using Fibroscan. Clin Res Hepatol Gastroenterol 2012;36:13-20.

10 Wong GL: Update of liver fibrosis and steatosis with transient elastography (Fibroscan $囚$ ). Gastroenterol Rep (Oxf) 2013;1:19-26.

11 Sasso M, Beaugrand M, de Ledinghen V, Douvin C, Marcellin P, Poupon R, Sandrin L, Miette V: Controlled attenuation parameter (CAP): a novel VCTE guided ultrasonic attenuation measurement for the evaluation of hepatic steatosis: preliminary study and validation in a cohort of patients with chronic liver disease from various causes. Ultrasound Med Biol 2010;36:1825-1835.

12 Mikolasevic I, Racki S, Lukenda V, Milic S, Pavletic-Persic M, Orlic L: Nonalcoholic fatty liver disease in renal transplant recipients proven by transient elastography. Transplant Proc 2014;46:1347-1352.

13 Mikolasevic I, Jelić I, Sladoje-Martinović B, Orlić L, Zivcić-Cosić S, Vuksanović-Mikulicić S, Mijić M, Racki S: Metabolic disorders in renal transplant recipients. Acta Med Croatica 2012;66:235-241.

14 Hricik D: Metabolic syndrome in kidney transplantation: management of risk factors. Clin J Am Soc Nephrol 2011;6:1781-1785.

15 Elahi T, Akhtar F, Ahmed E, Naqvi R: Prevalence of metabolic syndrome in renal transplant recipients - a single center experience. JPMA 2009;59:533.

16 Francazani AL, Burdick L, Raselli S, Pedotti P, Grigore L, Santorelli G, Valenti L, Maraschi A, Catapano A, Fargion S: Carotid artery intima-media thickness in nonalcoholic fatty liver disease. Am J Med 2008;121:72-78.

17 Villanova N, Moscatiello S, Ramilli S, Bugianesi E, Magalotti D, Vanni E, Zoli M, Marchesini G: Endothelial dysfunction and cardiovascular risk profile in nonalcoholic fatty liver disease. Hepatology 2005;42:473480.

18 Assy N, Dijbre A, Farah R, Grosovski M, Marmor A: Presence of coronary plaques in patients with nonalcoholic fatty liver disease. Radiology 2010;254:393-400.

19 Targher G, Bertolini L, Padovani R, Rodella S, Zoppini G, Zenari L, Cigolini M, Falezza G, Arcaro G: Relations between carotid artery wall thickness and liver histology in subjects with nonalcoholic fatty liver disease. Diabetes Care 2006;29:1325-1330.

20 Brea A, Mosquera D, Martin E, Arizti A, Cordero JL, Ros E: Nonalcoholic fatty liver disease is associated with carotid atherosclerosis: a case- control study. Arterioscler Thromb Vasc Biol 2005;25:1045-1050.

-21 Targher G, Day CP, Bonora E: Risk of cardiovascular disease in patients with nonalcoholic fatty liver disease. N Engl J Med 2010;363:1341-1350.

-22 Targher G, Bertolini L, Rodella S, Lippi G, Franchini M, Zoppini G, Muggeo M, Day CP: NASH predicts plasma inflammatory biomarkers independently of visceral fat in men. Obesity (Silver Spring) 2008;16:1394-1399.

23 Pinzani M: Pathophysiology of non-alcoholic steatohepatitis and basis for treatment. Dig Dis 2011;29:243248.

24 Petta S, Muratore C, Craxi A: Non-alcoholic fatty liver disease pathogenesis: The present and the future. Dig Liver Dis 2009:615-625. 